\title{
Lei de Falência, Acesso ao Crédito Empresarial e Taxas de Juros no Brasil
}

\author{
Bankruptcy Law, Credit and Interest Rates in Brazil
}

ANTONIO GLEDSON DE CARVALHO****

\begin{abstract}
RESUMO: A lei de falências é uma instituição econômica importante devido aos seus efeitos no crédito e, consequentemente, no desenvolvimento econômico e financeiro. Este fato levou vários países a revisar sua lei. Este artigo apresenta uma visão geral sobre o tema com foco no Brasil. Seus principais pontos são: o crédito no Brasil não é compatível com o nível de desenvolvimento do país; há evidências de que o Brasil está entre os países onde a proteção legal aos credores é pior; a experiência internacional mostra que mudanças na lei de falências afetam o mercado de crédito; e a lei brasileira é extremamente desatualizada. PALAVRAS-CHAVE: Lei de falências; crédito; taxa de juros.
\end{abstract}

ABSTRACT: Bankruptcy law is an important economic institution because of its effects on credit and, consequently, on financial and economic development. This fact has led several countries to revise their law. This article presents an overview on the topic focusing in Brazil. Its main points are: credit in Brazil is not compatible with the country level of development; there is evidence that Brazil is among the countries where legal protection to creditors is worst; the international experience shows that changes in the bankruptcy law affects the market for credit; and the Brazilian law is extremely outdated.

KEYWORDS: Bankruptcy law; credit; interest rates.

Jel Classification: E51; G33; K42.

\section{INTRODUÇÃO}

As legislações falimentares têm sido alvo de reformas em vários países durante as últimas décadas. Apesar de todas estas mudanças, enormes diferenças prevalecem entre as legislações dos diversos países. Entre organizações creditícias, políticos e

\footnotetext{
* Departamento de Contabilidade, Finanças e Controle da Escola de Administração de Empresas de São Paulo da Fundação Getúlio Vargas - EAESP/FGV, São Paulo-SP, Brasil. E-mail: Gledson @fgvsp.br. Submetido: agosto 2003; aceito: fevereiro 2004.

** Agradeço a Eduardo Luis Lundberg e Roberto Luis Troster pelos comentários e sugestões e à Febraban pelo apoio financeiro. Qualquer erro ou omissão é de minha exclusiva responsabilidade.
} 
mesmo acadêmicos existe muita diversidade de opiniões sobre o que seria a legislação ideal. A nossa Lei de Falências data de 1945 e é notoriamente ultrapassada. No âmbito do governo e de alguns segmentos da sociedade predomina a percepção de que a atual legislação é um obstáculo ao desenvolvimento econômico e que, portanto, a sua reforma é essencial. No entanto, as propostas de mudanças tocam em pontos que têm apelo emocional muito forte, como a redistribuição dos direitos entre credores, fisco e trabalhadores e a imposição de restrições sobre os procedimentos que a administração de uma empresa em insolvência financeira pode adotar. Por isso, as negociações e formação de consenso são morosas, retardando a reforma. Para se ter uma idéia, o atual projeto que visa alterar a legislação falimentar (Projeto de Lei 4.376/93) tramita no Congresso desde 1993, e somente no final de 2002, após o anúncio de que o governo do presidente Lula daria prioridade à reforma, o tópico começou a atrair a atenção da sociedade civil. A falta de debate sobre o tema ocasiona desinformação. Particularmente, nota-se a falta de textos que esclareçam a opinião pública sobre o tema. Este trabalho procura preencher esta lacuna, explorando a conexão entre legislação falimentar, acesso ao crédito empresarial e taxas de juros. Este artigo está estruturado da seguinte maneira: a Seção 2 discute o que é e quais são os objetivos da legislação falimentar. Explorar a relevância social desta legislação é o objetivo da Seção 3. Na seção 4 apresentamos um diagnóstico do crédito empresarial no Brasil, mostrando que este é inadequado, tanto em termos de taxas de juros, quanto no referente ao acesso. Na Seção 5 aprofundamos este diagnóstico por meio de comparações internacionais, as quais indicam a) que o crédito no Brasil está muito aquém do observado em países em estágio similar de desenvolvimento e b) que o Brasil está entre os países que menos protegem credores. A Seção 6 apresenta estudos internacionais que mostram que mudanças no nível de proteção aos credores afetam as taxas de juros e acesso ao crédito. A Seção 7 contém uma apresentação resumida da legislação atual e explora suas deficiências. Finalmente, a Seção 8 apresenta as conclusões.

\section{OS OBJETIVOS DA LEI DE FALÊNCIAS}

As empresas contratam empréstimos com bancos ou investidores (debenturistas) por várias razões: financiar projetos, adiantar recursos, pagar dívidas etc. Existem ocasiões em que algumas firmas não podem pagar os valores contratados ou cumprir seus compromissos. Denominamos tais situações como insolvência financeira. A legislação falimentar ou Lei de Falências é a peça que estabelece as normas e procedimentos a serem adotados quando uma firma se encontra em insolvência financeira.

Insolvência financeira não significa falta de viabilidade econômica para a empresa. Por exemplo: uma empresa pode encontrar-se em insolvência financeira devido a uma crise temporária no setor em que opera. A dificuldade também pode ser resultado de má gestão que pode ser corrigida. Uma vez superadas as dificuldades, a empresa pode voltar a ser lucrativa. Por outro lado, algumas empresas em estado de insolvência não apresentam qualquer viabilidade. Nestes últimos casos, 
os ativos da empresa geralmente valem mais que a própria empresa. Uma legislação falimentar ideal deveria, no primeiro caso, preservar a integridade da empresa por meio de uma recuperação (podendo envolver reescalonamento de dívidas, reestruturação societária etc.) e, no segundo, promover a liquidação da empresa, usando o caixa gerado para pagar as partes credoras (partes com haveres na empresa: empregados fornecedores, bancos, debenturistas, fisco etc.). A liquidação prematura de uma empresa viável é ineficiente, uma vez que muito do valor econômico e todo o valor social da empresa se perde. Por outro lado, a manutenção (ou reestruturação) de uma empresa economicamente inviável pode propiciar aos seus controladores a oportunidade de se beneficiarem à custa das outras partes credoras.

Distinguir cada um dos casos nem sempre é tarefa fácil, o que torna a operacionalização de uma legislação baseada no conceito de viabilidade econômica muito difícil, pois requer muito discernimento e rapidez por parte do Judiciário ${ }^{1}$. Alternativamente, as legislações falimentares geralmente focam na alocação de direitos às partes com interesse na empresa insolvente. Em muitos casos, o direito de uma parte pode implicar o fechamento da empresa. Por exemplo, no Reino Unido, credores que receberam algum ativo da empresa como garantia podem tomar posse do ativo, mesmo que isto inviabilize o negócio [Franks, Nyborg e Torous (1996)]. Uma legislação que proteja muito os credores pode induzir à liquidação de empresas viáveis (denominada liquidação ineficiente). Por outro lado, uma legislação que privilegie demasiadamente a recuperação das empresas pode permitir que empresas inviáveis continuem operando, dilapidando assim o seu patrimônio e prejudicando a partes credoras (denotaremos isto por reorganização ineficiente). Um exemplo notório de reorganização ineficiente foi a Eastern Airlines ${ }^{2}$, nos Estados Unidos: em 1989. Esta empresa, em estado de insolvência, propôs uma reestruturação ${ }^{3}$ que envolvia a venda de parte de seus ativos para cobrir despesas operacionais. $\mathrm{O}$ juiz da causa alegou que a manutenção da empresa era do interesse público e que isto era mais importante do que o interesse dos credores e aprovou o pedido dos administradores da Eastern Airlines. Ao final do processo, em 1991, a empresa foi finalmente liquidada por falta de viabilidade. No entanto, os credores receberam apenas uma fração do que teriam recebido se a empresa tivesse sido liquidada em 1989.

A) diferença de atitude de credores e controladores com relação à manutençãoda empresa ocorre porque o valor ao qual os credores têm direito é fixo. Isto gera uma assimetria: se uma empresa em estado de insolvência voltar a ser lucrativa, os controladores irão se beneficiar do lucro gerado; os credores, nem tanto. Por outro lado, se a empresa quebrar de

\footnotetext{
${ }^{1}$ Um dos exemplos de legislação baseada no conceito de viabilidade econômica é o Capítulo 11 da lei americana.

${ }^{2}$ Brigham e Gapensky (1997: cap. 24).

${ }^{3}$ A reestruturação nos EUA é denominada Capítulo 11.
} 
vez, a perda é exclusivamente dos credores (os acionistas pouco perdem, pois geralmente são os últimos na lista de prioridade sobre a massa falida). Assim, os credores são mais freqüentemente favoráveis à liquidação que os controladores.

Mesmo que a legislação induza a uma escolha ótima entre reestruturação e liquidação, resta um conflito distributivo nos casos de liquidação: o valor ao qual as partes credoras têm direito geralmente é superior ao valor da massa falida. Assim, existe a necessidade de uma regra para a partilha dos proventos gerados com a liquidação. Uma legislação, portanto, deve estabelecer normas tanto para a reestruturação quanto para a liquidação de empresas em insolvência financeira.

A partilha é vista, com freqüência, como um problema que afeta apenas partes privadas, existindo pouco interesse social. Por esta razão, tem sido continuamente enfocada pela ótica de méritos, procurando defender partes economicamente menos privilegiadas (no caso brasileiro, os trabalhadores). Esta abordagem, no entanto, é parcial e equivocada: os credores antecipam o resultado do conflito e consideram isto quando tomam suas decisões quanto a conceder crédito à empresa. Assim, deve-se examinar com atenção a maneira como a distribuição dos proventos de uma empresa, caso esta entre em insolvência financeira, afeta a decisão dos agentes e que impacto isto pode ter sobre o sistema econômico, mais notoriamente sobre crédito (acesso ao crédito empresarial, taxas de juros e spreads bancários), investimento, emprego, salários etc.

\section{A RELEVÂNCIA SOCIAL DA LEGISLAÇÃO FALIMENTAR}

Estudos recentes mostram que o desenvolvimento do crédito está relacionado ao nível de proteção a credores. Em especial, La Porta et al. (1997) mostram que o nível de proteção a credores e a qualidade do judiciário são determinantes do crédito: a razão entre crédito e PIB é maior em países que protegem mais os credores e apresentam maior eficiência no sistema judiciário. Adicionalmente, vários estudos demonstram que a taxa de crescimento de um país depende do nível de desenvolvimento da intermediação financeira [Goldsmith (1969), King e Levine (1993a), (1993b), (1993c)]. Pagano (1993) faz uma resenha do tópico.

A) racionalidade deste último resultado reside na função do sistema financeiroem alocar recursos (investimentos): o sistema econômico é caracterizado pela separação/distinção entre empreendedores e geradores de poupança (recursos disponíveis para investir). As cabeças com bons projetos e capacidade para geri-los não são necessariamente aquelas que possuem recursos para implementá-los O investimento é realizado por um número relativamente pequeno de pessoas, utilizando a poupança gerada por uma parcela grande da população. Assim, impõe-se a necessidade de um intermediador entre empreendedores e poupadores: o sistema financeiro. 
Por muito tempo a ciência econômica deu pouca importância à configuração do sistema financeiro. Acreditava-se que os recursos naturalmente fluem dos poupadores para os projetos mais produtivos. Esta percepção mudou ao longo das últimas décadas com o surgimento de vários argumentos, tanto de natureza teórica quanto empírica [Levine (1997) apresenta uma resenha extensiva do tópico]. Hoje sabemos que vários problemas de assimetria de informação (denominados seleção adversa) e enforcement $t^{4}$ de contratos (denominados moral hazard ou oportunismo) muitas vezes inviabilizam o financiamento de projetos altamente produtivos [ver Levine (1997)]. Estas são situações em que empresas com bom potencial enfrentam racionamento de crédito ou capital [Stiglitz e Weiss (1981), Calomiris e Hubbard (1990), Fazzari, Hubbard e Petersen (1988)]. Estas ineficiências ocasionam uma perda do potencial de crescimento.

A assimetria de informação refere-se a casos em que as partes possuem informações distintas. Isto ocorre, por exemplo, com o crédito: o tomador possui mais informação sobre suas reais possibilidades de saldar o financiamento do que o agente creditício. Em situações nas quais os bancos não conseguem avaliar precisamente a qualidade creditícia dos candidatos, o resultado é a negação generalizada de crédito. Quando isto ocorre, bons candidatos também têm o crédito negado (denominamos isto de racionamento de crédito). A maneira mais comum de amenizar esta ineficiência é o uso de colateral (ativos que os tomadores dão como garantia para os credores). No entanto, a eficácia do colateral depende da prontidão com a qual os credores podem se apossar do mesmo. Isto, por sua vez, é determinado pela legislação falimentar (como visto na seção anterior).

A percepção acerca da importância social do bom desempenho do sistema financeiro vem pautando a atuação de vários governos que vêem nas reformas e aperfeiçoamento deste um mecanismo para a promoção do desenvolvimento econômico. Exemplos disto são as reformas dos mercados de capitais, legislação societária (Lei das SA) e legislação falimentar (a Seção 5 apresenta algumas destas reformas). Neste artigo, enfocamos apenas esta última.

O baixo desenvolvimento do crédito tem outros custos além da redução na taxa de crescimento. $\mathrm{O}$ processo de internacionalização em curso tem mudado radicalmente as condições de competição e perspectivas para as empresas nacionais. Aquelas que não conseguem acessar fontes de capital a custos competitivos têm muito menos chances de sobreviver e acabam sendo alvo para aquisição ou simplesmente desaparecem. Um mercado financeiro pouco desenvolvido, que coloca fortes restrições financeiras sobre as empresas, pode acabar promovendo concentração de mercado e desnacionalização. Assim, a eficiência dos intermediários financeiros e do mercado de capitais é vital para garantir competitividade às empresas domésticas.

Finalmente, ressaltamos que há argumentos teóricos indicando que a restrição de crédito generalizada pode acabar por favorecer a concentração de renda: aque-

\footnotetext{
${ }^{4} \mathrm{O}$ termo inglês é usado devido à inexistência de termo equivalente em português.
} 
les que já possuem recursos (colateral) podem fazer bons investimentos quando as oportunidades se apresentam. O mesmo já não ocorre com os menos favorecidos. Deste modo, restrições financeiras impostas por um mau funcionamento do sistema financeiro podem acabar por promover a concentração de riqueza ${ }^{5}$.

\subsection{Um Exemplo da Relação entre Legislação Falimentar e Taxa de Juros}

Além do efeito da legislação falimentar sobre o acesso ao crédito empresarial, existe um importante efeito sobre a taxa de juros (ou spread bancário ${ }^{6}$ ). A seguir apresentamos um argumento simples para ilustrar a relação entre legislação falimentar e taxas de juros:

Suponha que um banco conceda empréstimos no valor total de $\$ 10.000$ na forma de empréstimos individuais no valor de $\$ 100$ para 100 firmas distintas. Assuma, ademais, que o custo do dinheiro para o banco seja $10 \%$ ao período (i.e., o banco capta recursos a $10 \%$ a.p. ou poderia aplicar seus recursos a $10 \%$ ). Isto significa que após um período o banco precisa reaver um total de $\$ 11.000$ de seus devedores. Caso não haja inadimplência, ou seja, todas as empresas paguem suas dívidas, basta cobrar $\$ 110$ de cada firma, o que equivale a uma taxa de $10 \%$.

Assuma, no entanto, que haja uma taxa de inadimplência de $10 \%$. Considere, também, que a legislação protege pouco os credores, de modo que quando a empresa entra em insolvência financeira o banco nada recebe. Isto significa que 90 empresas vão pagar o empréstimo e 10 nada pagarão. Agora, o banco tem de reaver os $\$ 11.000$ de apenas 90 empresas. Assim, cada uma terá de pagar

$$
\frac{11.000}{90}=\$ 122,22
$$

Isto representa uma taxa de juros de $22,22 \%$, ou equivalentemente, um spread bancário de $12,22 \%$.

Mantenha a mesma taxa de inadimplência, mas alternativamente suponha que haja uma reforma legislativa que garanta maior proteção aos credores. Agora, em caso de insolvência financeira, o banco consegue reaver $\$ 50$ por firma insolvente. Isto significa que, com o total das 10 empresas insolventes, o banco obterá $\$ 500$. Assim, é necessário obter das demais $11.000-500=\$ 10.500$. Deste modo, cada empresa adimplente terá de pagar

$$
\frac{11.000}{90}=\$ 122,22
$$

\footnotetext{
${ }^{5}$ Pelo nosso conhecimento, não existem trabalhos empíricos mostrando que o mau funcionamento do sistema financeiro favorece a concentração de renda. Isto em parte se deve à dificuldade técnica que o tema implica.

${ }^{6}$ Spread bancário é a diferença entre a taxa à qual os bancos captam recursos e a taxa cobrada em empréstimos a instituições não financeiras.
} 
o que representa uma taxa de juros de $16,67 \%$, ou equivalentemente, um spread bancário de $6,67 \%$.

É importante notar que a mudança da legislação, neste caso, tem um efeito direto sobre apenas 10 empresas de um total de 100 . No entanto, a queda da taxa de juros é bastante expressiva, 5,55\% (22,22 - 16,67) e se estende sobre todas as empresas.

Este exemplo, apesar de bastante simples, ilustra dois fatos extremamente importantes: 1) a legislação falimentar, por determinar quanto os bancos conseguem reaver dos inadimplentes, tem um impacto considerável sobre o nível das taxas de juros e 2) a ineficiência causada por uma legislação falimentar inadequada recai sobre os bons pagadores, que devem compensar os bancos pelo prejuízo causado pelos inadimplentes. Finalmente, cabe ressaltar que o argumento acima não implica que outros fatores também possam afetar as taxas de juros. Em particular, deve-se notar que o referencial competitivo do sistema bancário também é um fator importante. No entanto, este último elemento não está no escopo deste artigo.

\section{O CRÉDITO NO BRASIL}

O crédito empresarial no Brasil é notoriamente pouco desenvolvido: as taxas de juros praticadas são exorbitantes e acesso ao crédito, bastante restrito. Esta seção revê algumas das evidências existentes.

A extensão do racionamento de crédito empresarial predominante no Brasil está ilustrada na Tabela 1, extraída de Carvalho e Barcelos (2002). Estes autores usam uma amostra de empresas industriais que publicaram balanços no período entre 1994 e 1998 (predominantemente, sociedades anônimas). Podemos observar que cerca de $10 \%$ das grandes empresas - empresas com patrimônio superior a cerca de US\$ 30 milhões no período 1994-98 - não usam crédito de curto prazo (em $199487,05 \%$ das grandes empresas usaram crédito de curto prazo; em 1995, 88,87\% ; em 1996, 81,47\% , e assim por diante), enquanto $5 \%$ destas empresas não apresentam financiamento de longo prazo (em 1994 92,31\% das grandes empresas usaram crédito de longo prazo; em 1995, 94,76\%; em 1996, 92,36\%, e assim por diante). Entre as empresas médias, cerca de $30 \%$ não apresentam financiamento de curto prazo durante o período, ao passo que aproximadamente $16 \%$ não apresentam endividamento de longo prazo. Este quadro é ainda mais crítico entre as pequenas empresas, em que mais de $50 \%$ não apresentam financiamento de curto prazo e cerca de $45 \%$ não apresentam endividamento de longo prazo. Estes dados indicam que as empresas domésticas ou se defrontam com sérias restrições de crédito ou evitam se endividar (provavelmente devido às altas taxas de juros cobradas). Adicionalmente, devemos ressaltar que estes dados subestimam o problema do acesso ao crédito no Brasil, pois se baseiam em balanços disponibilizados pelas próprias empresas (sociedades anônimas, que são obrigadas por lei a publicar seus balanços e algumas limitadas que os publicaram voluntariamente). Estas 
empresas, pela sua projeção, são geralmente as que menos encontram restrições creditícias. Assim, acreditamos que o quadro creditício das pequenas empresas é ainda mais grave do que o reportado acima.

Tabela 1: Uso de Crédito por Classe de Tamanho de Empresas

Os números reportados nesta tabela se referem à proporção de empresas que apresentavam algum endividamento de curto ou longo prazo em seus balanços em cada um dos anos. Os valores de corte correspondem ao tamanho total dos ativos que dividem as empresas entre pequenas, médias e grandes.

\begin{tabular}{|c|c|c|c|c|c|}
\hline \multicolumn{2}{|l|}{ ANO } & \multirow{2}{*}{$\begin{array}{c}\text { Total de } \\
\text { Firmas } \\
533\end{array}$} & \multirow{2}{*}{$\begin{array}{l}\text { Crédito de } \\
\text { Curto Prazo } \\
87.05 \%\end{array}$} & \multirow{2}{*}{$\begin{array}{c}\text { Crédito de } \\
\text { Longo Prazo }\end{array}$} & \multirow{2}{*}{$\begin{array}{c}\begin{array}{c}\text { Valor de } \\
\text { Corte } \\
\text { US\$ mil }\end{array} \\
53.920\end{array}$} \\
\hline 1994 & Grande & & & & \\
\hline & Média & 518 & $74.71 \%$ & $82.24 \%$ & \\
\hline & Pequena & 517 & $48.55 \%$ & $58.03 \%$ & 14.050 \\
\hline & Total & 1568 & $70.28 \%$ & $77.68 \%$ & \\
\hline \multirow[t]{4}{*}{1995} & Grande & 611 & $88.87 \%$ & $94.76 \%$ & 57.691 \\
\hline & Média & 593 & $74.70 \%$ & $83.64 \%$ & \\
\hline & Pequena & 592 & $52.36 \%$ & $59.29 \%$ & 14.012 \\
\hline & Total & 1796 & $72.08 \%$ & $79.31 \%$ & \\
\hline \multirow[t]{4}{*}{1996} & Grande & 693 & $81.47 \%$ & $92.36 \%$ & 51.096 \\
\hline & Média & 673 & $54.74 \%$ & $78.87 \%$ & \\
\hline & Pequena & 672 & $32.23 \%$ & $45.66 \%$ & 10.606 \\
\hline & Total & 2038 & $56.37 \%$ & $72.45 \%$ & \\
\hline \multirow[t]{4}{*}{1997} & Grande & 745 & $91.01 \%$ & $95.30 \%$ & 28.680 \\
\hline & Média & 724 & $73.34 \%$ & $84.25 \%$ & \\
\hline & Pequena & 723 & $45.92 \%$ & $52.01 \%$ & 6.232 \\
\hline & Total & 2192 & $66.61 \%$ & $73.91 \%$ & \\
\hline \multirow[t]{4}{*}{1998} & Grande & 741 & $90.82 \%$ & $95.82 \%$ & 29.160 \\
\hline & Média & 720 & $73.33 \%$ & $85.42 \%$ & \\
\hline & Pequena & 720 & $46.53 \%$ & $56.11 \%$ & 6.052 \\
\hline & Total & 2181 & $70.43 \%$ & $79.28 \%$ & \\
\hline
\end{tabular}

Fonte: Carvalho e Barcelos (2002). 


\section{Gráfico 1: J uros Cobrados pelo S etor Bancário a Empresas e Spreads Bancários. \\ Valores anualizados (média móvel de 3 meses)}

Os juros reportados correspondem a uma média ponderada dos juros praticados nas seguintes operações: capital de giro, conta garantida, hot money, vendor, aquisição de bens, desconto de duplicatas e desconto de promissórias. Estas operações não incluem repasses via agências governamentais. O spread bancário aparece como a diferença entre os juros e o custo básico do capital (CDB).

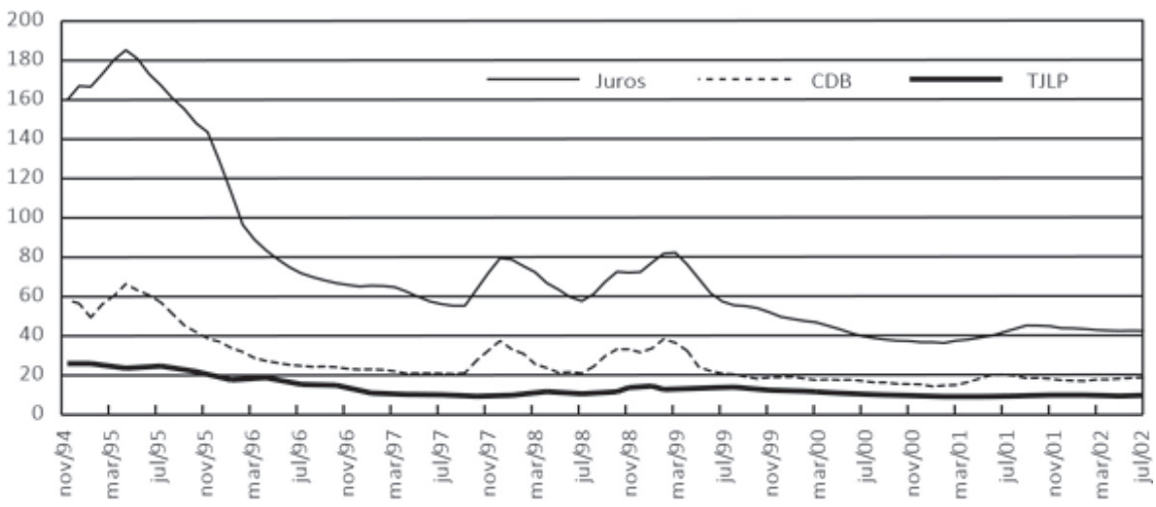

Fonte: Bacen (2002).

Outros elementos importantes para ilustrar a inadequação do crédito empresarial no Brasil são os níveis dos juros e spreads bancários, que estão entre os mais elevados do mundo. O Gráfico 1, retirado de Bacen (2002), mostra a taxa média de juros cobrada das empresas ${ }^{7}$ em operações de financiamento de capital de giro, a taxa de captação para o setor bancário $(\mathrm{CDB})$ e a taxa básica para repasses do Banco Nacional de Desenvolvimento Econômico e Social (BNDES) - o spread aparece como a diferença entre a primeira e a segunda. Como exemplo, em 1999 - ano em que tanto juros quanto spreads foram relativamente baixos - o custo médio dos empréstimos do setor bancário a empresas era 66\% aa., decompondose em $21 \%$ de custo de captação e $45 \%$ de spread. Naturalmente, taxas como estas inviabilizam o sistema bancário privado como fornecedor de crédito de longo pra$\mathrm{zO}^{8}$. Assim, o BNDES, que fornece crédito subsidiado, aparece como um dos únicos provedores de recursos de longo prazo.

As taxas de juros para as linhas de financiamento de longo prazo do BNDES são incomparavelmente mais baixas do que as taxas de juros para capital de giro praticadas pelos bancos privados (ver Gráfico 1). No entanto, o número de empre-

\footnotetext{
${ }^{7}$ Juros e Spreads Bancários no Brasil, relatório do Departamento de Estudos e Pesquisas do Banco Central do Brasil, 1999.

${ }^{8}$ A cobrança de taxas de juros elevadas para empréstimos de curto prazo é viável, pois no curto prazo existe alguma previsibilidade quanto à situação financeira das empresas (resultando em relativamente baixa inadimplência). A mesma taxa, se cobrada em empréstimos de longo prazo, resultaria numa taxa de inadimplência exorbitante.
} 
sas que acessam estas linhas de crédito é relativamente pequeno, pois: 1) o volume de recursos do BNDES é inferior à necessidade das empresas domésticas e 2) como estas linhas de financiamento são repasses feitos pelo sistema bancário privado (o banco originador estrutura a operação, concede o empréstimo com os recursos do BNDES e é solidário em caso de inadimplência), a obtenção de recursos de longo prazo está condicionada aos padrões de análise dos bancos privados. Deste modo, a empresa que não consegue obter financiamento de bancos privados dificilmente acessa as linhas do BNDES. Quando nos defrontamos com estas evidências, concluímos que o crédito empresarial no Brasil é muito caro e extremamente restrito.

\section{COMPARAÇÕES INTERNACIONAIS}

\subsection{Crédito}

Na seção anterior mostramos que o crédito no Brasil é bastante limitado, tanto em termos de acesso quanto em termos de custo (taxas de juros). A seguir, por meio de comparações internacionais, adicionamos mais evidências. A Tabela 2 contém dados sobre volume de crédito bancário como proporção do PIB durante o período 1994-97 para uma amostra dos 48 principais países da Organização para Cooperação e Desenvolvimento Econômico (OECD). Esta é a medida agregada mais comum de desenvolvimento do crédito. Em especial, ela provê uma indicação do potencial para melhoria. Podemos observar que o crédito bancário no Brasil está muito aquém do padrão de países em nível de desenvolvimento similar: a média brasileira é de $46,7 \%$ - correspondendo à trigésima oitava posição -, padrão comparável ao de países como Colômbia, Índia, México e Paquistão. Alguns países em estágio similar de desenvolvimento, como Malásia, Tailândia e Hong Kong, apresentam valores em torno de $150 \%$. Para outros, como Cingapura, Egito, Coréia do Sul, Portugal, Israel e Grécia, o indicador está entre 70\% e 80\%. Se, por um lado, isto indica que o crédito no Brasil é muito pouco desenvolvido, por outro, mostra que podemos obter ganhos expressivos caso possamos adequar as nossas instituições.

Por fim, cabe mencionar que algumas comparações internacionais, baseadas em dados de empresas de capital aberto [Glen e Pinto (1994), Singh (1994) e Dermiguc-Kunt e Maksimovic (1995)] mostram que o uso de financiamento de longo prazo pelas empresas brasileiras é baixo, mesmo quando comparado com aquelas de países em estado de desenvolvimento semelhante [Leal (2001) revê esta literatura]. Dermiguc-Kunt e Maksimovic (2000) oferecem evidências mais contundentes ao mostrar que nossas empresas enfrentam sérias restrições financeiras e crescem mais lentamente que aquelas de vários países.

\subsection{Direito dos Credores}

Segundo nosso conhecimento, La Porta et al. (1997) apresentam a única comparação extensiva no que diz respeito a direitos de credores pelo mundo. Esta seção 
se baseia neste trabalho. Inicialmente destacamos que uma comparação sobre direito de credores é bastante complexa: existem vários tipos de credores com interesses distintos. Proteger alguns credores pode equivaler a diminuir os direitos de outros. Por exemplo, no caso de insolvência, credores segurados podem simplesmente preferir a posse do colateral dado como garantia, mesmo que isto signifique a liquidação da empresa. Por outro lado, credores quirografários (sem garantias) podem preferir a manutenção da empresa por meio de uma reestruturação, na esperança de receber algo caso ela venha a se tornar lucrativa. Ao acessar os direitos dos credores, estes autores assumem a perspectiva dos credores segurados.

Tabela 2: Crédito ao Setor Privado,

PIB e PIB per capita pelo Mundo (Médias de 1994 a 1997)

\begin{tabular}{|c|c|c|c|c|c|c|}
\hline \multirow[t]{2}{*}{ País } & \multicolumn{2}{|c|}{$\begin{array}{l}\text { Crédito ao Setor Privado } \\
\text { (proporção do PIB) }\end{array}$} & \multicolumn{2}{|c|}{$\begin{array}{l}\text { PIB per capita } \\
\text { (US\$ milhares) }\end{array}$} & \multicolumn{2}{|c|}{$\begin{array}{c}\text { PIB } \\
\text { (US\$ bilhões) }\end{array}$} \\
\hline & valor & ranking & valor & ranking & valor & ranking \\
\hline Japão & 293 & (1) & 23,1 & (5) & 5.231 & (2) \\
\hline Suíça & 182 & $(2)$ & 24,8 & (3) & 308 & (14) \\
\hline África do Sul & 157 & (3) & 7,2 & (32) & 135 & (26) \\
\hline Hong Kong & 154 & (4) & 23,4 & (4) & 143 & (25) \\
\hline Bélgica & 151 & (5) & 21,9 & (8) & 276 & (17) \\
\hline Malásia & 138 & (6) & 7,4 & (31) & 91 & (30) \\
\hline Tailândia & 136 & (7) & 6,4 & (34) & 169 & (23) \\
\hline EUA & 134 & (8) & 27,7 & (1) & 7.241 & (1) \\
\hline Alemanha & 133 & (9) & 20,6 & (12) & 2.430 & (3) \\
\hline Áustria & 129 & (10) & 21,5 & (10) & 235 & (18) \\
\hline Reino Unido & 125 & (11) & 19,7 & (16) & 1.122 & (5) \\
\hline Holanda & 121 & (12) & 20,1 & (13) & 405 & (11) \\
\hline Espanha & 106 & (13) & 15,1 & $(22)$ & 567 & (9) \\
\hline França & 101 & (14) & 21,3 & (11) & 1.548 & (4) \\
\hline Suécia & 99 & (15) & 19,2 & (17) & 231 & (19) \\
\hline Canadá & 98 & (16) & 21,7 & (9) & 582 & (8) \\
\hline Itália & 96 & (17) & 19,7 & (15) & 1.088 & (6) \\
\hline Portugal & 93 & (18) & 13,4 & (23) & 107 & (29) \\
\hline Jordânia & 93 & (19) & 3,4 & (39) & 7 & (47) \\
\hline Nova Zelândia & 89 & (20) & 17,0 & $(21)$ & 61 & (38) \\
\hline Grécia & 88 & $(21)$ & 12,1 & (25) & 115 & (28) \\
\hline Israel & 84 & $(22)$ & 17,6 & (20) & 88 & (31) \\
\hline Austrália & 83 & (23) & 19,8 & (14) & 368 & $(12)$ \\
\hline Egito & 83 & (24) & 2,8 & (42) & 61 & (39) \\
\hline Cingapura & 77 & (25) & 26,0 & (2) & 88 & (32) \\
\hline Noruega & 75 & (26) & 23,0 & (6) & 151 & (24) \\
\hline
\end{tabular}




\begin{tabular}{lllllll}
\hline Coréia do Sul & 74 & $(27)$ & 12,5 & $(24)$ & 470 & $(10)$ \\
Irlanda & 73 & $(28)$ & 18,1 & $(19)$ & 67 & $(36)$ \\
Filipinas & 68 & $(29)$ & 3,3 & $(40)$ & 77 & $(34)$ \\
Finlândia & 65 & $(30)$ & 18,7 & $(18)$ & 129 & $(27)$ \\
Chile & 62 & $(31)$ & 11,6 & $(26)$ & 61 & $(40)$ \\
Dinamarca & 55 & $(32)$ & 22,4 & $(7)$ & 184 & $(21)$ \\
Indonésia & 53 & $(33)$ & 3,2 & $(41)$ & 209 & $(20)$ \\
Quênia & 52 & $(34)$ & 1,1 & $(47)$ & 9 & $(46)$ \\
Paquistão & 51 & $(36)$ & 1,5 & $(46)$ & 62 & $(37)$ \\
Zimbábue & 51 & $(35)$ & 2,2 & $(44)$ & 7 & $(48)$ \\
Índia & 49 & $(37)$ & 1,5 & $(45)$ & 346 & $(13)$ \\
Brasil & 46 & $(38)$ & 6,2 & $(35)$ & 712 & $(7)$ \\
Colômbia & 44 & $(39)$ & 6,6 & $(33)$ & 81 & $(33)$ \\
México & 42 & $(40)$ & 8,0 & $(30)$ & 303 & $(15)$ \\
Uruguai & 38 & $(41)$ & 8,6 & $(28)$ & 19 & $(43)$ \\
Equador & 37 & $(42)$ & 4,8 & $(37)$ & 18 & $(44)$ \\
Sri Lanka & 34 & $(43)$ & 2,3 & $(43)$ & 13 & $(45)$ \\
Turquia & 31 & $(44)$ & 5,8 & $(36)$ & 176 & $(22)$ \\
Venezuela & 27 & $(45)$ & 8,5 & $(29)$ & 77 & $(35)$ \\
Argentina & 25 & $(46)$ & 9,6 & $(27)$ & 297 & $(16)$ \\
Nigéria & 19 & $(47)$ & 0,9 & $(48)$ & 29 & $(42)$ \\
Peru & 12 & $(48)$ & 4,4 & $(38)$ & 60 & $(41)$ \\
\hline Fonti:or) & \\
\hline
\end{tabular}

Fonte: World development Indicators (1999), World Bank.

O índice de direitos dos credores aqui apresentado baseia-se em quatro critérios. Para cada critério satisfeito, soma-se um ponto. O índice corresponde a esta soma. Os critérios são os seguintes: 1) em alguns países, o processo de reorganização garante à empresa insolvente o uso de seus ativos. Isto impede que os credores segurados de se apossem de ativos, mesmo que estes tenham sido dados como garantia. Este critério atribui um ponto para países nos quais os credores segurados podem se apossar de ativos dados como garantia em caso de reorganização; 2) em alguns países, credores segurados não têm prioridade absoluta sobre ativos da empresa em caso de liquidação. No Brasil, por exemplo, trabalhadores e fisco têm prioridade. Este critério atribui um ponto quando credores segurados têm prioridade absoluta sobre os proventos da massa falida; 3) algumas legislações fazem da reestruturação um favor legal que a empresa pode obter sem o consentimento de seus credores. Um exemplo disto é a concordata no Brasil. Este critério atribui um ponto a países nos quais o consentimento dos credores é necessário para a reestruturação; e 4) o último critério refere-se ao direito de gestão de uma empresa em reestruturação. Nos Estados Unidos e Brasil, por exemplo, os controladores permanecem na direção. Já na Malásia, os controladores são substituídos por pessoal 
indicado por um tribunal ou pelos credores [La Porta el al. (1997)]. Este critério atribui um ponto a países nos quais os acionistas não detêm automaticamente o controle em caso de reorganização.

A Tabela 3 apresenta o índice de direitos dos credores pelo mundo. Podemos observar que o Brasil é um dos países que menos oferecem proteção aos credores (somando apenas um ponto). Os campeões de proteção a credores (somando 4 pontos) são Cingapura, Egito, Equador, Hong Kong, Índia, Indonésia, Israel, Malásia, Nigéria, Paquistão, Quênia, Reino Unido e Zimbábue, enquanto os que menos protegem (zero pontos) são Colômbia, Filipinas, França, México e Peru.

Devemos notar, em particular, que o Brasil é um dos poucos países em que credores segurados não têm prioridade absoluta quando da liquidação da empresa. Os outros países nos quais isto ocorre são Nova Zelândia, Sri Lanka, Grécia, Colômbia, Filipinas, França, México e Peru. A prioridade absoluta dos credores é um elemento extremamente importante, pois permite que a empresa acesse crédito, usando os seus ativos como garantia.

Tabela 3: Direitos dos Credores no Mundo

\begin{tabular}{|c|c|c|c|c|c|}
\hline País & $\begin{array}{l}\text { Restrição à } \\
\text { firma } \\
\text { para reter } \\
\text { ativos } \\
\text { quando em } \\
\text { reestruturação }\end{array}$ & $\begin{array}{l}\text { Prioridade } \\
\text { dos } \\
\text { Credores } \\
\text { segurados } \\
\text { em caso de } \\
\text { falência }\end{array}$ & $\begin{array}{c}\text { Restrições } \\
\text { para } \\
\text { entrar em } \\
\text { reestruturação }\end{array}$ & $\begin{array}{l}\text { Interventor } \\
\text { em caso de } \\
\text { reestruturação }\end{array}$ & $\begin{array}{l}\text { Índice de } \\
\text { direitos dos } \\
\text { Credores }\end{array}$ \\
\hline Cingapura & 1 & 1 & 1 & 1 & 4 \\
\hline Egito & 1 & 1 & 1 & 1 & 4 \\
\hline Equador & 1 & 1 & 1 & 1 & 4 \\
\hline Hong Kong & 1 & 1 & 1 & 1 & 4 \\
\hline Índia & 1 & 1 & 1 & 1 & 4 \\
\hline Indonésia & 1 & 1 & 1 & 1 & 4 \\
\hline Israel & 1 & 1 & 1 & 1 & 4 \\
\hline Malásia & 1 & 1 & 1 & 1 & 4 \\
\hline Nigéria & 1 & 1 & 1 & 1 & 4 \\
\hline Paquistão & 1 & 1 & 1 & 1 & 4 \\
\hline Quênia & 1 & 1 & 1 & 1 & 4 \\
\hline Reino Unido & 1 & 1 & 1 & 1 & 4 \\
\hline Zimbábue & 1 & 1 & 1 & 1 & 4 \\
\hline África do Sul & 0 & 1 & 1 & 1 & 3 \\
\hline Alemanha & 1 & 1 & 1 & 0 & 3 \\
\hline Áustria & 1 & 1 & 1 & 0 & 3 \\
\hline Coréia do Sul & 1 & 1 & 0 & 1 & 3 \\
\hline Dinamarca & 1 & 1 & 1 & 0 & 3 \\
\hline Nova Zelândia & 1 & 0 & 1 & 1 & 3 \\
\hline Sri Lanka & 1 & 0 & 1 & 1 & 3 \\
\hline
\end{tabular}




\begin{tabular}{|c|c|c|c|c|c|}
\hline Tailândia & 1 & 1 & 0 & 1 & 3 \\
\hline Bélgica & 1 & 1 & 0 & 0 & 2 \\
\hline Chile & 0 & 1 & 1 & 0 & 2 \\
\hline Espanha & 1 & 1 & 0 & 0 & 2 \\
\hline Holanda & 0 & 1 & 1 & 0 & 2 \\
\hline Itália & 0 & 1 & 1 & 0 & 2 \\
\hline Japão & 0 & 1 & 0 & 1 & 2 \\
\hline Noruega & 0 & 1 & 1 & 0 & 2 \\
\hline Suécia & 0 & 1 & 1 & 0 & 2 \\
\hline Taiwan & 1 & 1 & 0 & 0 & 2 \\
\hline Turquia & 0 & 1 & 1 & 0 & 2 \\
\hline Uruguai & 0 & 1 & 0 & 1 & 2 \\
\hline Argentina & 0 & 1 & 0 & 0 & 1 \\
\hline Austrália & 0 & 1 & 0 & 0 & 1 \\
\hline Brasil & 0 & 0 & 1 & 0 & 1 \\
\hline Canadá & 0 & 1 & 0 & 0 & 1 \\
\hline $\begin{array}{l}\text { Estados Uni- } \\
\text { dos }\end{array}$ & 0 & 1 & 0 & 0 & 1 \\
\hline Finlândia & 0 & 1 & 0 & 0 & 1 \\
\hline Grécia & 0 & 0 & 0 & 1 & 1 \\
\hline Irlanda & 0 & 1 & 0 & 0 & 1 \\
\hline Portugal & 0 & 1 & 0 & 0 & 1 \\
\hline Suíça & 0 & 1 & 0 & 0 & 1 \\
\hline Filipinas & 0 & 0 & 0 & 0 & 0 \\
\hline Colômbia & 0 & 0 & 0 & 0 & 0 \\
\hline França & 0 & 0 & 0 & 0 & 0 \\
\hline México & 0 & 0 & 0 & 0 & 0 \\
\hline Peru & 0 & 0 & 0 & 0 & 0 \\
\hline
\end{tabular}

Fonte: La Porta \& Lopez-de-S ilanes \& S hleifer \& Vishny (1998).

\section{EVIDÊNCIAS SOBRE REFORMAS E EFEITOS SOBRE CRÉDITO}

Como discutido na Seção 2, o reconhecimento da importância da legislação falimentar para o crédito e, conseqüentemente, para o desenvolvimento econômico tem levado vários países a aperfeiçoá-la. Dentre estes merecem destaque: Estados Unidos$^{9}$ (1978 e 1994), França (1985 e 1994), Alemanha (1994), Reino Unido ${ }^{10}$

\footnotetext{
${ }^{9}$ Bankruptcy Reform Act de 1978 e sua revisão em 1994.

10 Companies Act de 1995 e Insolvency Act de 1996.
} 
(1995 e 1996) e, na América Latina, Argentina ${ }^{11}$ (1995), Costa Rica ${ }^{12}$ (1996), Peru ${ }^{13}$ (1996) e Colômbia ${ }^{14}$ (1989 e 1999). Apresentamos, a seguir, algumas evidências sobre reformas legislativas e seus efeitos sobre crédito.

Scott e Smith (1986) analisam os efeitos das mudanças na legislação falimentar dos EUA (o Bankruptcy Reform Act de 1978) que modificou a relação entre empresas em insolvência financeira e seus credores. Algumas das principais modificações estabeleceram que:

1) caso uma empresa peça falência ou reestruturação (Chapter 11), seus credores devem cessar qualquer esforço de cobrança. Isto efetivamente impede que credores segurados possam se apropriar de colateral (ativos dados como garantia) sem autorização do tribunal;

2) uma vez requerida a falência ou reestruturação, os bancos não têm direitode se apossar de valores da empresa em custódia do banco (por exemplo, depósitos, recebimentos etc.);

3) em alguns casos o plano de reestruturação pode ser aprovado sem a concordância de alguns credores;

4) sejam impostas restrições sobre o que uma empresa em reestruturação podefazer com ativos dados como garantia a credores; e

5) nos casos de falência pessoal, a legislação estabelece algumas isenções partedo patrimônio sobre os quais os credores não têm qualquer direito. Nesta reforma, foi determinando, no âmbito federal, o direito a algumas isenções. Além disso, o Congresso Federal concedeu aos Estados o direito de fixar seus próprios níveis de isenção. O devedor pode optar entre a isenção federal ou estadual.

Estes autores argumentam e mostram evidências de que essas modificações na legislação falimentar dos EUA tiveram um impacto sobre o custo dos empréstimos para os bancos, fazendo com que as taxas de juros em empréstimos empresariais subissem.

Berkowitz e White (2002), estudando o efeito da mudança na legislação dos EUA, argumentam que tanto as taxas de juros quanto o volume de crédito que as pequenas empresas obtêm são afetados pela legislação falimentar: quando uma empresa é estruturada como uma private ownership - o que no Brasil equivaleria a uma firma individual ${ }^{15}$-, o empresário responde com seu patrimônio pessoal pelas dívidas da empresa. Se esta fracassa, o empresário tem a vantagem de pedir falência pessoal (como alternativa à falência da empresa), pois passa a ter direito a certas isenções (por exemplo, somente o patrimônio pessoal acima de um certo

\footnotetext{
${ }^{11}$ Ley de Concursos y Quiebras, $\mathrm{n}^{\circ}$ 24.522, julho de 1995.

${ }^{12}$ Lei no 7643, Reforma del Título del Código Processal, outubro de 1996.

${ }^{13}$ Ley de Reorganización del Patrimonio, Decreto Legislativo nº 845, outubro de 1996.

${ }^{14}$ Decreto no 350 de 1989 e Lei n ${ }^{\circ} 550$ de 1999.

${ }^{15}$ No Brasil, esta categoria foi extinta com o novo código civil.
} 
valor pode ser seqüestrado para repagar os credores ${ }^{16}$ ). Quanto maior o nível de isenção, menor a garantia que os credores têm quanto ao recebimento dos empréstimos. Por outro lado, quando a empresa é estruturada como uma corporation (o que no Brasil equivale a uma sociedade limitada), o empresário não responde com seu patrimônio pelas dívidas da empresa. O Bankruptcy Reform Act de 1978 permite aos diversos estados americanos escolher os níveis de isenção. Assim, este varia de estado para estado. Este estudo mostra que pequenas empresas (private ownerships) situadas em estados com maior nível de isenção mais freqüentemente encontram restrição de crédito e, caso recebam crédito, a taxa de juros cobrada é maior e o tamanho dos empréstimos, menor.

Sumariando, os estudos existentes sobre o impacto de alterações na legislação falimentar americana fortalecem o argumento de que redução no direito dos credores acaba por elevar as taxas de juros e reduzir o volume de empréstimos que empresas individuais obtêm.

\section{A LEGISLAÇÃO FALIMENTAR BRASILEIRA}

A lei de falência em vigor no Brasil, Decreto Lei no 7.661 , foi decretada por Getúlio Vargas em 21 de junho 1945. Embora tenha sido um avanço em sua época, esta lei tornou-se inadequada para as necessidades de uma economia moderna. Dentre as suas principais limitações, destacam-se: 1) é desnecessariamente rígida; 2) não oferece condições para a recuperação de empresas economicamente viáveis em estado de insolvência financeira; 3 ) burocratiza excessivamente o processo de liquidação de empresas; 4) não otimiza os proventos da massa falida por afastar do processo os credores que são os agentes mais aptos para conduzi-la; e 5) dificulta a obtenção de crédito pelas empresas. Esta seção busca descrever resumidamente a atual legislação (Subseção 7.1) e comentar algumas de suas principais limitações (Subseção 7.2).

\subsection{A Lei Atual}

Esta seção, baseada em Rowat e Astigarraga (1999), faz uma apresentação resumida da legislação atual. Pela legislação falimentar brasileira, existem dois dispositivos legais para firmas em insolvência financeira: 1) a falência, que consiste numa liquidação supervisionada pelo judiciário e 2) a concordata, que é um dispositivo para reescalonar ou reduzir os pagamentos devidos a credores não-segurados. A seguir descrevemos estes procedimentos.

\footnotetext{
${ }^{16}$ Estas isenções incluem muitas vezes a casa própria (até um determinado valor) e uma outra isenção para outros bens patrimoniais.
} 


\subsubsection{A Concordata}

A concordata é um dispositivo pelo qual um devedor insolvente renegocia sob supervisão judicial sua dívida com os credores não-segurados. Os acionistas continuam a gerir o negócio, enquanto pagam aos credores não-segurados ${ }^{17}$ (quirografários). Quando concedida, a concordata impede qualquer ação dos credores nãosegurados (quirografários) para coletar seus haveres. Isto, no entanto, não se estende às dívidas com credores segurados. Existem duas modalidades de concordata: a suspensiva e a preventiva. A distinção diz respeito ao tempo do preenchimento da mesma - se anterior ou posterior à decretação da falência. A concordata pode assumir a forma de uma moratória, um abatimento da dívida ou uma combinação das duas.

Para ser candidato a uma concordata preventiva, dentre outros requisitos, o devedor deve estar em funcionamento há mais de dois anos, não ter nenhum título protestado, não ter pedido concordata no prazo de cinco anos e não ter tido sua falência decretada. Durante a vigência da concordata os acionistas continuam no controle da empresa, mas sujeitos à supervisão de um comissário indicado pelo judiciário. Dentre outras tarefas, cabe ao comissário indicar um contador para verificar os créditos e ativos do devedor. $\mathrm{Na}$ concordata preventiva, o devedor deve propor aos credores não-segurados um plano de pagamento que respeite os seguintes critérios:

a) pagamento à vista de pelo menos $50 \%$ da dívida total, quando a concordata propõe um abatimento;

b) pagamento de $60 \%, 75 \%, 90 \%$ e $100 \%$ quando os termos de pagamento são 6,12, 18 e 24 meses, respectivamente;

c) nenhum abatimento é permitido se o plano é uma moratória em que o pagamento é efetuado depois de 18 meses;

d) em qualquer caso, a dívida deve ser liquidada em 24 meses; e

e) se o plano levar mais de 12 meses, pelo menos dois quintos da dívida devem ser resgatados ao final do primeiro ano.

Caso preencha determinados requisitos, uma empresa que já teve sua falência decretada pode ter esta convertida em uma concordata suspensiva. Por esta, os acionistas retomam o controle da empresa e seus ativos, condicionados a pagar aos credores não-segurados de acordo com critérios mínimos especificados:

a) quando a concordata propõe um abatimento, o pagamento à vista deve ser de pelo menos $35 \%$ aos credores não-segurados (quirografários);

b) pagamento de $50 \%$ é requerido, provido que esta não se estenda por um

\footnotetext{
${ }^{17}$ A concordata não evita a ação dos credores segurados. No entanto, há uma tática conhecida como "concordata branca": os devedores ameaçam os credores segurados de pedir falência, o que reduz drasticamente os direitos dos credores segurados. Em resposta, os credores segurados freqüentemente acabam por negociar com o devedor.
} 
prazosuperior a 2 anos e que pelo menos dois quintos sejam pagos durante o primeiro ano; e

c) dívidas relativas à previdência, impostos, salários e aquelas contraídas pelamassa falida antes da concessão da concordata preventiva devem ser pagas dentro do prazo de 30 dias da concessão da concordata suspensiva.

Deve-se observar que os critérios para a obtenção de uma concordata suspensiva são menos restritivos que os necessários para uma concordata preventiva. Uma concordata pode ser rescindida com base em vários argumentos, como, por exemplo, o pagamento a alguns credores que prejudique os demais ou falha em cumprir o plano de pagamento estipulado.

\subsubsection{A Falência}

A falência é um procedimento judicial para a coleta, disposição e liquidação dos ativos de uma empresa ${ }^{18}$ insolvente. Este processo, conduzido por um síndico indicado pelo tribunal responsável, termina com a distribuição dos proventos às partes credoras, de acordo com a seguinte ordem de prioridade:

1) dívidas trabalhistas;

2) dívidas fiscais e previdenciárias;

3) dívidas seguradas (com garantias reais);4) dívidas quirografárias (sem garantias reais); e 5) acionistas.

A falência pode ser requerida somente por um credor não-segurado, pelo próprio devedor, seus herdeiros, sócios ou acionistas. Para que um credor segurado possa pedir a falência de um devedor é necessário que abra mão dos ativos dados como garantia ou que prove que o valor destes ativos não é suficiente para liquidar seus créditos.

Caso a falência seja decretada, os procedimentos legais envolvem duas fases: 1) verificação dos ativos e passivos da massa falida e 2) liquidação e distribuição dos proventos. O tribunal que decreta a falência deve apontar um síndico. A lei dá preferência a que o maior credor residente na comarca seja o síndico da massa falida. Caso os credores declinem desta indicação, o juiz tem liberdade para indicar um síndico dativo.

A primeira fase da falência consiste em coletar e lacrar todos os bens da empresa, levantar um quadro de credores e preparar um inventário dos bens e ativos da massa falida. Em alguns casos em que a manutenção da atividade da empresa seja conveniente, o tribunal pode indicar um administrador para gerenciar a empresa. No entanto, todas as transações devem ser liquidadas à vista. Isto, na prática, inviabiliza a manutenção das atividades. Cada um dos credores deve ter sua

\footnotetext{
${ }^{18}$ Algumas empresas, dentre elas bancos, sociedades de capitalização, empresas de seguros, sociedades anônimas de previdência privada e outras, têm um procedimento de liquidação especial, diferente do aqui descrito.
} 
dívida habilitada judicialmente. Assim, a existência de conflitos entre credores e a contabilidade da empresa pode tornar esta fase extremamente morosa.

Como existe a possibilidade de que o proprietário da empresa retome o controle por meio de uma concordata suspensiva, a liquidação dos ativos (segunda fase) é feita somente após a conclusão da primeira fase. A lei estipula que a liquidação seja feita por meio de leilões públicos.

\subsection{As limitações da Lei Atual}

A nossa atual legislação falimentar é bastante inadequada tanto para promover a recuperação de empresas viáveis como para liquidar as julgadas inviáveis. Esta seção que procura explorar as limitações da lei baseia-se em Bacen (2002).

\subsubsection{Ineficácia na Recuperação de Empresas}

Como apresentado na Seção 7.1.1, a concordata nada mais é do que um reescalonamento ou abatimento de dívidas e, por isto, não constitui um mecanismo efetivo para a reestruturação das empresas ${ }^{19}$. As suas principais limitações são:

a) prevê alívio em termos de reescalonamento ou abatimento apenas para as dívidas quirografárias (sem garantias reais). Os credores com garantias reais podem executá-las e obter a posse de ativos que sejam essenciais para o funcionamento da empresa, comprometendo, assim, a recuperação da mesma;

b) os prazos e porcentuais são muito rígidos (liquidação da dívida em 24 meses e pagamento de pelo menos $50 \%$ da dívida total ao fim do primeiro ano). Isto torna muito pouco viável a recuperação efetiva das empresas;

c) é um alívio que a empresa pode obter à revelia dos seus credores. Para a

obtenção da concordata não é necessária nem a apresentação de um plano de reestruturação, nem a concordância dos credores. Deste modo, a avaliação da viabilidade da empresa fica a cargo do Judiciário, que reconhecidamente tem pouca destreza para avaliar a viabilidade econômica de empresas;

d) dificulta um acordo extrajudicial entre credores e empresas, já que para isto é necessário que este obtenha a aprovação de todos os credores. A necessidade de consenso estimula que algum dos credores sempre discorde do acordo, de modo a obter maiores vantagens, mesmo que o acordo proposto lhe seja vantajoso;

e) não prevê senioridade das novas dívidas: as modernas legislações falimentaresestabelecem senioridade ${ }^{20}$ para as novas dívidas contratadas pela empresa durante o período de reestruturação com o objetivo de facilitar a manutenção das operações da firma. Caso contrário, a obtenção de crédito de fornecedores e bancos

\footnotetext{
19 Segundo comentários de vários advogados, na maioria dos casos a concordata é seguida pela decretação de falência, servindo apenas de um favor legal para adiar o que é inevitável. No entanto, este autor desconhece qualquer estudo sobre este aspecto.

${ }^{20}$ Com isto, estas dívidas devem ser `antes que as demais contraídas anteriormente o sejam.
} 
pode inviabilizar as operações de uma empresa, mesmo que esta seja economicamente viável.

\subsubsection{Ineficiência na Liquidação}

O principal objetivo da liquidação deve ser a maximização dos proventos da massa falida, procurando preservar o seu valor econômico e social. Neste aspecto, a nossa legislação é bastante inadequada. As suas principais deficiências são:

a) a ordem de prioridade sobre os proventos da massa falida elimina do pro-cesso os agentes mais qualificados para conduzi-lo: empresas com dificuldades financeiras buscam por todos os meios gerar caixa. $\mathrm{O}$ procedimento mais comum é o atraso de impostos, salários e encargos trabalhistas. Assim, as dívidas trabalhistas e fiscais de empresas insolventes são geralmente muito elevadas. Como a lei prioriza as dívidas trabalhistas e fiscais, raramente sobram recursos da massa para os demais credores. Por esta razão, estes geralmente declinam da indicação para síndico da massa falida, obrigando o juiz a indicar um síndico dativo. Uma vez que a liquidação passa a ser conduzida por um agente sem participação (interesse) no montante a ser realizado, cresce a probabilidade de o processo ser ineficiente. Devese notar que isto pode ser prejudicial até mesmo para os trabalhadores e o fisco. Mais importante ainda, a pequena possibilidade de os financiadores da empresa receberem algum valor quando a liquidação acaba, inviabilizando uma empresa sã de utilizar seus ativos como garantia para a obtenção de crédito;

b) a prioridade das dívidas trabalhistas também tem sido explorada pelos acionistas como uma maneira de expropriar as demais partes credoras: uma vez que a insolvência acontece, o controlador registra familiares como empregados com salários absurdamente altos. Deste modo, a indenização a estes últimos consome parte significante da massa falida e tem prioridade sobre as demais dívidas;

c) o encerramento de todas as atividades, acompanhadas do fechamento e lacração da empresa, é inadequado para a preservação do valor econômico e social da empresa. Esta prática pode ser defensável para pequenas empresas, mas com certeza imprópria para grandes e médias empresas: por causa da rápida obsolescência de ativos quando a manutenção é inadequada, e da importância cada vez maior de ativos não tangíveis - valor da marca, clientela, ponto comercial etc. -, o fechamento da empresa ou a demora na liquidação judicial acaba por causar a desvalorização dos bens de capital da empresa, perda de ativos intangíveis, produção e emprego;

d) o processo de liquidação prevê que a venda dos ativos ocorra por meio de leilões públicos tradicionais. Essa prática pode ser inadequada para promover a efetiva participação dos possíveis interessados. Ela também permite a manipulação por determinados grupos: na presença de competidores, estes aumentam sua oferta de modo a não permitir que os eventuais participantes arrematem quaisquer ativos. Uma vez que os participantes eventuais, desestimulados, deixam de comparecer aos leilões, esses grupos obtêm a vantagem de poder arrematar os lotes sem 
competição. Processos alternativos, como leilões com propostas seladas e via internet, deveriam ser previstos;

e) não há prioridade para que os ativos de uma empresa sejam vendidos em conjunto. Quando os ativos da empresa são leiloados separadamente, alguns ativos, pela sua liquidez, são valorizados. Outros ativos que são específicos àquela atividade empresarial perdem valor, pois nem sempre podem ser usados separadamente. Como exemplo, consideremos o imóvel e o equipamento feito para as medidas daquele imóvel. O leilão individual dos ativos atrai maior competição para o imóvel, mas deprecia violentamente os demais ativos (feitos sob medida para o imóvel, ou intangíveis, tais como o ponto comercial). Talvez o mais importante seja que a venda individual dos ativos não privilegia a aquisição por aqueles que queiram manter o uso produtivo da massa falida; e

f) a legislação não prevê juros para as dívidas da massa falida (apenas correção monetária). Deste modo, quanto mais longo o processo, mais vantajoso para os acionistas, pois ativos tangíveis (como imóveis) se valorizam, ao passo que as dívidas não. Isto estimula os acionistas a buscar todas as brechas legais para retardar ao máximo o processo de liquidação, na esperança de que, passados alguns anos, o valor do ativo supere o do passivo.

\section{CONCLUSÕES}

A legislação falimentar é um marco importante nas instituições econômicas de um país, pois tem importantes impactos sobre a recuperação das empresas em estado de insolvência financeira e sobre o desenvolvimento financeiro (acesso ao crédito empresarial e taxas de juros cobradas das empresas). Com base na experiência internacional, que mostra que o desenvolvimento financeiro afeta positivamente o desenvolvimento econômico, vários países têm revisto suas legislações falimentares de modo a adequá-las às necessidades de uma economia moderna.

No Brasil, no âmbito do governo e em alguns segmentos da sociedade, predomina a percepção de que a lei de 1945 é um obstáculo ao desenvolvimento econômico e que, portanto, a sua reforma é essencial. No entanto, as propostas de mudanças tocam em pontos que têm apelo emocional muito forte, e por esta razão caminham lentamente: o atual projeto de lei tramita no Congresso deste 1993 e somente no final de 2002, após o anúncio de que o governo daria prioridade à reforma da Lei de Falências, o tópico começou a atrair a atenção da sociedade civil.

Neste trabalho procuramos estabelecer uma visão panorâmica do tópico. As principais conclusões são: 1) o crédito no Brasil é incompatível com o nosso nível de desenvolvimento econômico, quer em termos de taxas de juros, quer em termos de acesso ao crédito empresarial; 2) os dados mostram que o Brasil está entre os países que menos protegem credores; 3 ) evidências internacionais mostram que mudanças na legislação falimentar alteram significativamente o mercado de crédi- 
to, quer em termos de taxas de juros, quer em termos de acesso ao crédito e 4) a atual legislação falimentar brasileira é inadequada, tanto para promover a recuperação de empresas em insolvência financeira quanto para promover uma liquidação eficiente das julgadas inviáveis.

\section{REFERÊNCIAS BIBLIOGRÁFICAS}

BACEN (Banco Central do Brasil) (2002) "Economia bancária e crédito - avaliação de três anos do projeto juros e spread bancário".

BERKOWITZ, J. e M. WHITE (2002) “Bankruptcy and Small Firms' Access to Credit”, NBER working paper, 9010, Cambridge, MA.

BRIGHAM E. e L. GAPENSKY (1997) Financial Management, Theory and Practice. Fort Worth, Texas: Dryden Press, $8^{a}$ edição.

CALOMIRIS, C. e G. HUBBARD (1990) “Firm Heterogeneity, Internal Finance and Credit Rationing”. Economic Journal, vol. 100: 90-104.

CARVALHO, A. G. e L. C. BARCELOS (2002) "Determinantes do acesso ao crédito empresarial no Brasil", working paper, IPE-USP.

DERMIGUC-KUNT, A. e V. MAKSIMOVIC (1995) "Capital Structure in Developing Countries: Evidence From Ten Country Cases”, World Bank working papers.

DERMIGUC-KUNT, A. e V. MAKSIMOVIC (2000) "Funding Growth in Bank-Based o Market-Based Financial Systems: Evidence from Firm-Level Data”, World Bank working papers.

FAZZARI, S.M., R.G. HUBBARD e B.C. PETERSEN (1988) "Investment and Finance Reconsidered", Brooking Papers on Economic Activity, 141-195.

FRANKS, J., K. NYBORG e W. TOROUS (1996) "A Comparison of US, UK and German Insolvency Codes”. Financial Management, vol. 25 (3): 86-101.

GLEN, J e B. PINTO (1994) “Debt or Equity? How Firms in Developing Countries Choose”. Washington: International Finance Corporation discussion paper.

GOLDSMITH, R. (1969) Financial Structure and Development. New Haven/CT: Yale University Press.

KING, R. e R. LEVINE (1993a) “Financial Intermediation and Economic Development”. In: Mayer, Colin e Vives, Xavier. Financial Intermediation in the Construction of Europe, Londres: Center for Economic Policy Research: 156-189.

KING, R. e R. LEVINE (1993b) “Finance and Growth: Schumpeter Might Be Right”. Quarterly Journal of Economics, vol. 108 (3): 717-737.

KING, R. e R. LEVINE (1993c) “Finance, Entrepreneurship and Growth: Theory and Evidence”. Journal of Monetary Economics, vol. 32 (3): 513-542.

LA PORTA, R., F. LOPEZ-DE-SILANES, A. SHLEIFER e R. VISHNY (1997) “Legal Determinants of External Finance". Journal of Finance, vol. 52 (3): 1131-1150.

LA PORTA, R., F. LOPEZ-DE-SILANES, A. SHLEIFER e R. VISHNY (1998) “Law and Finance". Journal of Political Economy, vol. 106 (6): 1113-1155.

LEAL, R. P. C. (2001) "A Review of the Empirical Evidence and of the Factors that Influence Brazilian Business Financing”, Coppead-UFRJ working paper.

LEVINE, R. (1997) "Financial Development and Economic Growth: Views and Agenda". Journal of Economic Literature, vol. 35 (julho): 688-726.

PAGANO, M. (1993) "Financial Markets and Growth: an Overview". European Economic Review, vol. 37 (2-3): 613-622.

ROWAT, M. e J. ASTIGARRAGA (1999) “Latin American Insolvency Systems”. World Bank Technical Paper $n^{\circ} 433$, Washington DC. 
SCOTT, J. A. e T. C. SMITH (1986) “The Effect of the Bankruptcy Reform Act of 1978 on Small Business Loan Pricing”. Journal of Financial Economics, vol. 16: 119-140.

SINGH A. (1994) "How Do Large Corporations in Developing Countries Finance Their Growth?". Finance and the International Economy, Oxford University Press: 120-142.

STIGLITZ, J. e A. WEISS (1981) “Credit Rationing in Markets with Imperfect Information”. American Economic Review, vol. 71 (3): 393-410. 